\title{
Incremental fishing gear modifications fail to significantly reduce large whale serious injury rates
}

\author{
Richard M. Pace III*, Timothy V. N. Cole, Allison G. Henry \\ Northeast Fisheries Science Center, National Marine Fisheries Service, 166 Water Street, Woods Hole, MA 02543, USA
}

\begin{abstract}
A major and immediate goal of the US Marine Mammal Protection Act is the reduction of marine mammal mortality incidental with commercial fishing operations. Under articles of the Act, the Atlantic Large Whale Take Reduction Plan (ALWTRP) was developed and implemented to reduce entanglement mortality of North Atlantic right whales Eubalaena glacialis, Gulf of Maine humpback whales Megaptera novaeangliae, and western North Atlantic fin whales Balaenoptera physalus by requiring modifications to commercial fishing gear (i.e. pots and sink gillnets). Although they undercount the number of entanglements, counts of detected incidents of entanglements and entanglement-related mortality are the primary index to entanglement mortality. We analyzed the annual counts of large whale entanglements including serious injuries and mortalities attributed to entanglements to evaluate the effectiveness of the ALWTRP from 1999 to 2009. The annual number of mortality events (including serious injuries) related to fishing gear entanglements averaged 2.5 for right whales, 6.5 for humpbacks, 0.6 for fin whales, and 2.4 for minke whales $B$. acutorostrata. Annual entanglement rates increased during the study period, but evidence for increased rates of entanglement-related mortality was equivocal. No significant changes occurred in waiting time (the number of days between entanglement events) in response to any management measures implemented to reduce large whale mortalities between 1998 and 2009, implying that these measures were generally ineffective in abating whale deaths from entanglements in fishing gear.
\end{abstract}

KEY WORDS: By-catch $\cdot$ Human-caused mortality $\cdot$ Large whales $\cdot$ Efficacy tests

\section{INTRODUCTION}

Cetaceans, including large whales, frequently become entangled in commercial fishing gear, and some entanglements result in injuries that may lead to the whale's death (Moore et al. 2005). In the USA, all entanglements, regardless of their lethality, constitute 'a take' or form of harassment that the Marine Mammal Protection Act (MMPA) and the Endangered Species Act (ESA) are intended to restrict. When human-caused mortality exceeds a prescribed threshold value, the MMPA compels the US government, in this case the National Marine Fisheries Service (NMFS; US Department of Commerce), to convene a take reduction team to develop rules to

\footnotetext{
*Corresponding author: richard.pace@NOAA.gov
}

reduce human-caused mortality related to commercial fishing within the exclusive economic zone (EEZ) of the USA. In developing take reduction plans, NMFS convenes meetings of stakeholders, primarily state government representatives, fishing industry participants, conservation advocates, and academic scientists, in an attempt to negotiate practical mitigation measures through consensus agreements. Regulations may target both lethal and non-lethal takes, and it is important that NMFS can demonstrate that a reduction in entanglements results from these rules. The set of rules described in the Atlantic Large Whale Take Reduction Plan (ALWTRP) (National Marine Fisheries Service 2007) attempts to reduce entanglement mortality of North Atlantic right

Outside the USA @ The US Government 2014. Open Access under Creative Commons by Attribution Licence. Use, distribution and reproduction are unrestricted. Authors and original publication must be credited. Publisher: Inter-Research · www.int-res.com 
whales Eubalaena glacialis, Gulf of Maine humpback whales Megaptera novaeangliae, and western North Atlantic fin whales Balaenoptera physalus by stipulating fishing restrictions and requirements for modifications to commercial pot fishing gear and sinking gillnets in the temperate western North Atlantic.

Ideally, the best indicator of the biological effectiveness of ALWTRP rules would be to compare measures of the incidence of entanglement or mortality rate due to entanglement both before and after regulations are in place. If we could estimate the cause-specific mortality due to entanglement at different times, we could gauge the effectiveness of regulations and measure the influence of entanglement on demographic patterns. However, the logistics of studying wild cetaceans renders estimates of causespecific mortality unlikely in the near future. Most whales die far from shore, and few carcasses are discovered for which the cause of mortality can be reasonably assured. Finally, detectability rates may vary significantly among causes of mortality so that observed proportions of detected causes may be unreliable estimates (Williams et al. 2011). This detection issue influences any measure of incidence rates, such that records of entanglement or mortality due to entanglement likely represent a small subset of actual entanglements. Using counts of incidents to judge effectiveness requires an assumption that the fraction of detected entanglements is not greatly influenced by the rate of occurrence and has a constant expectation throughout the time series being examined. Because unbiased estimates of annual numbers of entanglements, mortality due to entanglement, or even population sizes are not available, the basic data of raw counts of detected entanglements and deaths are the only direct measure of fisheries interactions with large whales.

We evaluated the ALWTRP's (National Marine Fisheries Service 2007) effectiveness in meeting the stated management goals directed at stocks of several baleen whales that spend significant time in US waters off the northeastern US coast. These rules attempt to reduce entanglement mortality of North Atlantic right whales, Gulf of Maine humpback whales, and western North Atlantic fin whales by regulating both commercial pot and sink gillnet fisheries. We note that with the exception of right whales, we are referencing stocks which are subpopulations recognized in US regulations as spending significant time in US waters. We were particularly interested in entanglement data prior to the enactment of a relatively contentious regulation referred to as the 'ground line rule', which requires fishers to use sinking lines in their gear configurations (National Marine Fisheries Service 2008). We believed that if the ALWTRP rules were effective, there would be a reduction in entanglement-related deaths and concomitantly in the detection of such deaths for these whale stocks, as well as for the Canadian east coast minke whale (Balaenoptera acutorostrata) stock, which is common in the same US waters. Specifically, we examined entanglement event data to determine the basic character of the event time series from 1999 through 2009. We also used simulation to examine the power of these methods, including an assessment of the influence of population change on the discovery of decreased incidence rates.

\section{METHODS}

Large whale entanglements were detected opportunistically by a wide range of observers, including biologists, commercial fishermen, commercial whale watchers, recreational boaters, and others. They were reported to the NMFS primarily through the Atlantic Large Whale Disentanglement Network and formal marine mammal stranding networks along the east coast of the USA and Canada. Those reports were evaluated by the Northeast Fisheries Science Center as part of a federal process to quantify serious injuries and mortalities (e.g. Henry et al. 2011). Here, those data were used to examine temporal patterns in reported entanglements of right, humpback, fin, and minke whales from 1 January 1999 through 31 December 2009. We removed all entanglements with strong evidence that they occurred outside the US EEZ (first seen entangled east of Halifax, Nova Scotia, or entangled in Canadian gear) and those entangled in gear from fisheries not regulated by the ALWTRP (principally fish weirs). We evaluated 2 data sets: all entanglements, and the subset of entanglements judged to result in mortality or serious injury. Hereafter, the term mortality will refer to any known dead animals or those judged to have received serious injuries caused by fishery interactions that, according to NMFS guidelines, would likely result in death.

We examined these data in 2 different forms: the annual counts and the waiting times between detected events. Counts per unit time and waiting times are 2 measures associated with the same process, and either type of data may be used to evaluate rates of events through time. Annual counts of entanglement and mortality events for each species should resemble a Poisson process, each with its own 
inherent rate, and can be summarized with generalized linear models for Poisson data. Waiting times, which we defined as the numbers of days elapsed between the discovery dates of 2 subsequent events, are a continuous analog to the count data and may offer advantages when analyzing relatively rare events. In particular, they have a cumulative distribution along a time axis that may inform our examinations. Based on a simulation experiment, Pace (2011) concluded that waiting times were more sensitive than counts per unit time for detecting modest changes (e.g. 50\% reduction) when annual detections averaged fewer than 10. Because rates of entanglement detections are low, we focused our analysis on waiting times.

\section{Statistical analysis}

We conducted pair-wise comparisons of annual rates of entanglements between stocks, and calculated generalized linear models of annual counts and 'waiting times' to judge competing hypotheses about changes in entanglement rates through time. For each of the 4 stocks, we first examined the waiting time data relative to fits of models of exponential waiting times assuming a constant mean annual rate of entanglement. We estimated the mean exponential waiting time over the entire period and plotted the empirical cumulative distribution against a theoretical one with the estimated mean as its sole parameter. Second, we examined pair-wise plots of counts of entanglements between stocks to look for common patterns and evaluated Poisson regressions for pairs that appeared correlated. We combined all event data in the same model allowing 'species' as a possible predictor, and we fit a series of generalized linear models (McCullagh \& Nelder 1989) to counts and their associated waiting times between events. Competing models were, in ascending order of complexity with regard to time:

(1) a single constant rate (null model);

(2) species-specific intercepts and a constant rate through time;

(3) species-specific intercepts plus 2 different rates representing the time frames of the initial ALWTRP and the subsequent expanded gear modifications beginning in 2002 (a breakdown of regulation changes over time appears in the supplemental material in van der Hoop et al. 2013);

(4) species-specific intercepts and a linearly (in the link) changing rate through time;

(5) species-specific intercepts plus a quadratic mo- del of continuous time to accommodate possible multiple reductions in entanglements or entanglementrelated mortalities over time;

(6) species-specific intercepts plus variable rates among years (i.e. 11 rates, 1 per year 1999-2009); and

(7) species-specific rates (i.e. species by continuous time interaction).

To count data, we fit analogous logistic regression models to examine evidence for changes in the proportions of mortalities observed per detected entanglement. All models were developed using the generalized linear model ('glm') procedure in R (ver. 2.14) (R Development Core Team 2011). Model comparisons were based on corrected Akaike's information criterion (AICc) and associated weight of evidence calculations for likelihood models (Anderson 2008). When there was no clear best model, we used modelaveraged predictions calculated using the $\mathrm{R}$ package 'AICcmodavg' (ver. 1.24) to summarize relationships.

Evaluations of similar data suggested that a relatively powerful approach for detecting changes may be to develop regressions of event times against order of occurrence (cumulative waiting time for an event versus its occurrence), and to compare models with and without change points (Pace 2011). The approach is attractive in that one can visualize and test for divergence (change point) occurring when a specific conservation measure is enacted or becomes effective. However, arranging the data thusly likely imputes an auto-correlated error structure which bears consideration, and because the predictor is now order of occurrence, the method is most suitable for one species at a time or pooled events. The ALWTRP rules have been amended in ways that presumably would have increased protection to whales during the study period, so we fit generalized least squares models (Pinheiro \& Bates 2000) to event times allowing for auto-correlated errors to examine the evidence for a change in the rate of entanglement and entanglement mortality detections in the period 1999 to 2009. Specifically, competing models were (Fig. 1):

(8) a single slope (a constant rate, not shown in Fig. 1);

(9) a fixed change point having 2 slopes coinciding with initial ALWTRP and expanded gear modifications in 2002;

(10) a fixed change point having 2 slopes on either side of the implementation date for another set of expanded gear modifications (starting with an entanglement prior to 5 October 2008); and

(11) a linear model with a quadratic term to test for curvilinear change over the study period. 

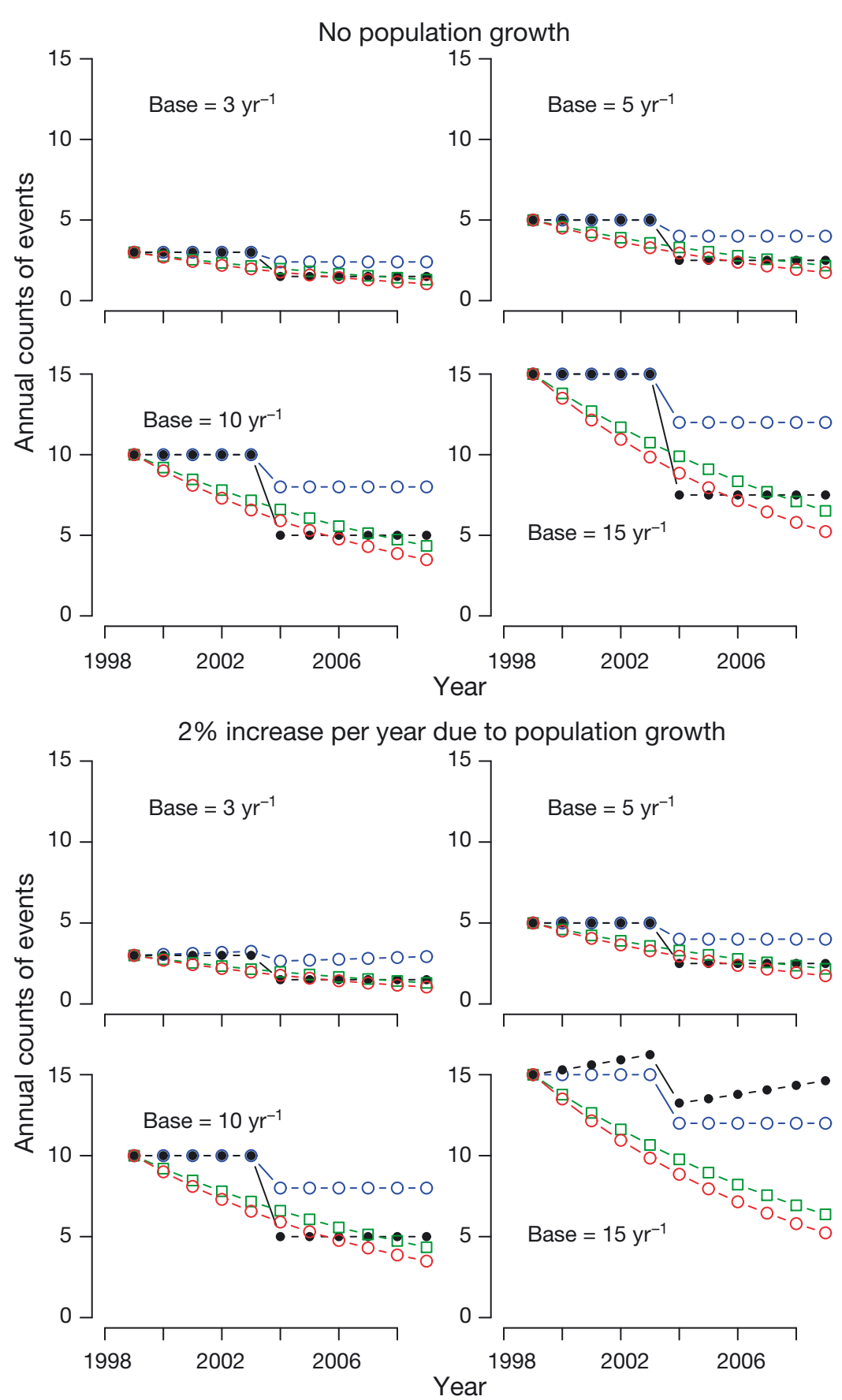

Fig. 1. Experimental conditions (i.e. true mean event rates) for simulations to test the power of statistical models to detect deviations in exponential waiting times due to conservation measures that reduce event rates under no growth and $2 \%$ growth scenarios. Each color represents 4 different patterns of change in entanglement mortalities. Constant rate is absent but shown are a $33 \%$ reduction in Year 5, a 50\% reduction in Year 5, and an 8\% drop per year dure in R for calculations. Model comparisons were based on AICc and associated weight of evidence calculations for likelihood models (Anderson 2008).

\section{Simulation experiments}

We were interested in the general sensitivity of the above analyses to these kinds of moderately low observed rates of occurrence over similar short time frames. So, in addition to evaluating the available records of detected entanglements and the subset leading to mortalities, we examined the potential to detect a change in rates of events using a set of simulation trials. Specifically, we simulated sets (1000 each) of randomly generated exponential waiting times that could occur over an $11 \mathrm{yr}$ period if the rates of occurrence of events were generated under the following set of experimental conditions:

(1) Base rates of 3, 5, 10, or 15 events per year; and

(2) Changes to the base rate (effects) within a time series diminished at 8 or $10 \%$ per year, or alternatively, after the first event occurring in Year 5, base rates would decrease by 0,33 , or $50 \%$

This yielded 20 experimental settings with known mean rates of event occurrence (see Table 1). For each simulated data set, we fit the following models using either a glm or generalized least squares (gls):

(1) Constant count of events each year (Poisson, glm)

(2) Two mean rates, one for Years 1-5 and the other for Years 6-11 (Poisson, glm)

(3) Graduated rate change (Poisson, glm)

(4) Constant waiting times across years (Gamma, glm)

To examine whether population growth might act to obscure substantial conservation benefits, we replicated the above experimental conditions assuming annual 2\% growth (Fig. 1). We used the 'gls' proce-
(5) Different mean waiting times for Years 1-5 and Years 6-11 (Gamma, glm)

(6) Gradually changing mean waiting time over the study period (Gamma, glm) 
(7) Event time series with a constant slope (gls, auto-correlated errors)

(8) Segmented regression allowing the slope of the event time series to change at the start of Year 6 (gls, auto-correlated errors)

(9) Linear regression including a quadratic term to allow for continuous change over the event time series (gls, auto-correlated errors).

For each trial, we used deviance tests to make the following model comparisons: 2 vs. 1, 3 vs. 1, 5 vs. 4 , 6 vs. 4,8 vs. 7 , and 9 vs. 7 . The percent rejections (alpha $=0.05)$ were taken as Type I errors under no change, or as measure of power to detect a true change for the 20 combinations of 4 base levels and 5 effects.

\section{RESULTS}

Whale events evaluated by the Northeast Fisheries Science Center for the $11 \mathrm{yr}$ period prior to enactment of the ground-line rule (1999-2009) included 167, 59, 62, and 22 records of entanglements of humpback, right, minke, and fin whales, respectively, of which $72,28,26$, and 7 were classified as serious injuries or mortalities. Comparisons of counts of entanglements and mortalities between species showed little agreement, except that annual right whale entanglements were correlated with those of humpback whales (Poisson regression with log link: slope $=0.082 \pm 0.30 \mathrm{SE}[\mathrm{Pr}>$ $|Z|=0.0058]$ probability of a greater absolute $Z$-statistic). Empirical distributions of species-specific waiting times had the same general appearance of exponential random variables generated by theoretical distributions derived using the calculated means as the theoretical mean. Close inspection of these comparisons gave the impression of a slight lack-of-fit due to excessive clustering of shorter waiting times (Fig. 2), but there was no substantive statistical evidence that single species models of waiting times were different from a constant Poisson process through time.

Generalized linear models provided substantial evidence that counts of entanglements and mortalities due to entanglement and their associated waiting times were not consistent during the study period (Table 1). Substantial differences in base rates were exhibited among species, with humpback entanglements and mortalities reported more than twice as frequently as those of right and minke whales, which were much more common than those of fin whales. Annual counts of detected entanglements increased, and waiting times slightly decreased during the study period (Fig. 3A,B), but results from entanglement-related mortalities were less clear. Counts of detected mortalities were relatively constant, with a small increase occurring after 2002, whereas model-averaged predictions of waiting times between mortalities slightly increased (Fig. 3C,D). Our logistic model provided

Table 1. Results of generalized linear models of waiting times between entanglements or mortalities due to entanglement for 4 species of baleen whales (Balaenoptera acutorostrata, B. physalus, Eubalaena glacialis, Megaptera novaeangliae) in the Atlantic exclusive economic zone (EEZ) from 1999 to 2009. K: no. of parameters in the model; AICc: corrected Akaike's information criterion

\begin{tabular}{|c|c|c|c|c|c|}
\hline Model & $\mathrm{K}$ & $\mathrm{AICc}$ & $\triangle \mathrm{AICc}$ & $\begin{array}{c}\text { AICc } \\
\text { weight }\end{array}$ & $\begin{array}{c}\text { Cumulative } \\
\text { weight }\end{array}$ \\
\hline \multicolumn{6}{|l|}{ Entanglement counts } \\
\hline Species + Year & 5 & 203.84 & 0 & 0.52 & 0.52 \\
\hline Species + Quadratic(Year) & 6 & 205.28 & 1.44 & 0.25 & 0.77 \\
\hline Species +2 Periods & 5 & 206.26 & 2.42 & 0.15 & 0.92 \\
\hline Species & 4 & 208.96 & 5.12 & 0.04 & 0.96 \\
\hline Species $\times$ Year & 8 & 209.22 & 5.38 & 0.04 & 1 \\
\hline Species + Factor(Year) & 14 & 218.38 & 14.54 & 0 & 1 \\
\hline Constant & 1 & 343.19 & 139.34 & 0 & 1 \\
\hline \multicolumn{6}{|l|}{ Entanglement waiting times } \\
\hline Species + Quadratic(Year) & 7 & 420.54 & 0 & 0.55 & 0.55 \\
\hline Species & 5 & 422.95 & 2.42 & 0.16 & 0.71 \\
\hline Species + Year & 6 & 423.06 & 2.52 & 0.15 & 0.86 \\
\hline Species + Factor(Year) & 15 & 424.59 & 4.05 & 0.07 & 0.94 \\
\hline Species +2 Periods & 6 & 424.96 & 4.42 & 0.06 & 1 \\
\hline Species $\times$ Year & 9 & 430.85 & 10.32 & 0 & 1 \\
\hline Constant & 2 & 471.64 & 51.1 & 0 & 1 \\
\hline \multicolumn{6}{|c|}{ Mortality + Serious injury counts } \\
\hline Species & 3 & 134.05 & 0 & 0.5 & 0.5 \\
\hline Species + 2 Periods & 4 & 134.96 & 0.91 & 0.32 & 0.81 \\
\hline Species + Year & 4 & 136.65 & 2.6 & 0.14 & 0.95 \\
\hline Species + Quadratic(Year) & 5 & 139.43 & 5.39 & 0.03 & 0.98 \\
\hline Species $\times$ Year & 6 & 140.88 & 6.84 & 0.02 & 1 \\
\hline Species + Factor(Year) & 13 & 153.69 & 19.65 & 0 & 1 \\
\hline Constant & 1 & 159.32 & 25.27 & 0 & 1 \\
\hline \multicolumn{6}{|c|}{ Mortality + Serious injury waiting times } \\
\hline Species + Year & 5 & 358.07 & 0 & 0.38 & 0.38 \\
\hline Species & 4 & 358.08 & 0.01 & 0.37 & 0.75 \\
\hline Species +2 Periods & 5 & 360.42 & 2.35 & 0.12 & 0.86 \\
\hline Species + Quadratic(Year) & 6 & 360.48 & 2.4 & 0.11 & 0.98 \\
\hline Species $\times$ Year & 7 & 363.74 & 5.67 & 0.02 & 1 \\
\hline Constant & 2 & 373.09 & 15.01 & 0 & 1 \\
\hline Species + Factor(Year) & 14 & 375.88 & 17.81 & 0 & 1 \\
\hline
\end{tabular}



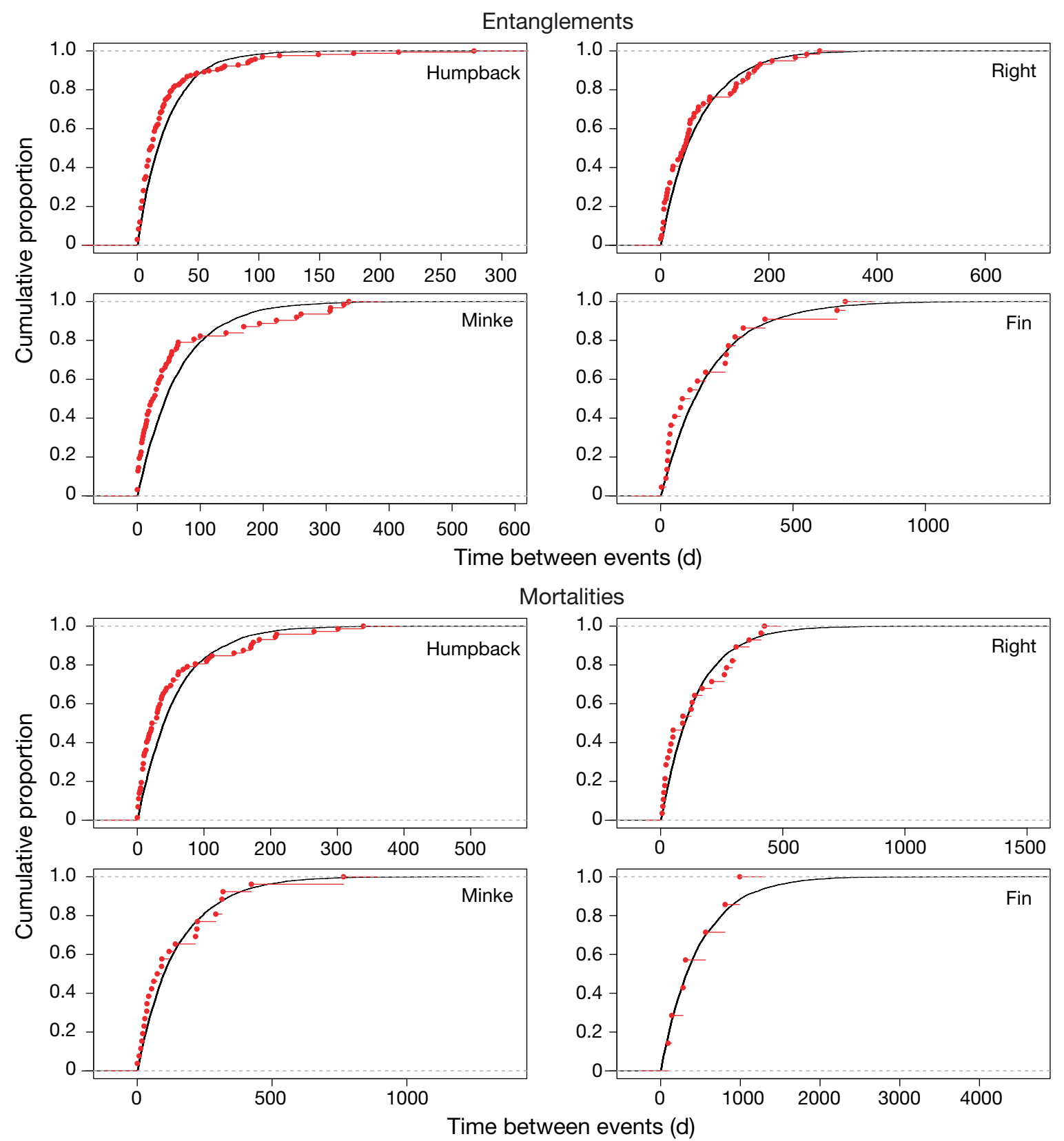

Fig. 2. Empirical cumulative distributions (red lines with dots) plotted against their theoretical distributions (solid black lines) derived from using means of waiting times between detected entanglements or mortalities due to entanglements for 4 species of large whales (humpback whale Megaptera novaeangliae; right whale Eubalaena glacialis; minke whale Balaenoptera acutorostrata; fin whale B. physalus) monitored in the Atlantic US exclusive economic zone (EEZ) from 1999 to 2009 . Note the different $x$-axis scales

evidence for a declining trend in the probability that a detected entanglement would be classified as a mortality or serious injury, and that the species being monitored had little influence on proportions (Table 2, Fig. 4). In the case of minke whale mortalities due to entanglement, a model that predicted decreased death rates per detected entanglement over time (quadratic fit; Table 3) had about twice the supporting evidence than the model fitting only a constant rate.

Our tests of the cumulative waiting times for entanglements and their related mortalities varied somewhat among species (Fig. 5). In general, there was modest to little evidence to support deviation in either the entanglement rate or the lethal entanglement rate from a constant rate during the study 


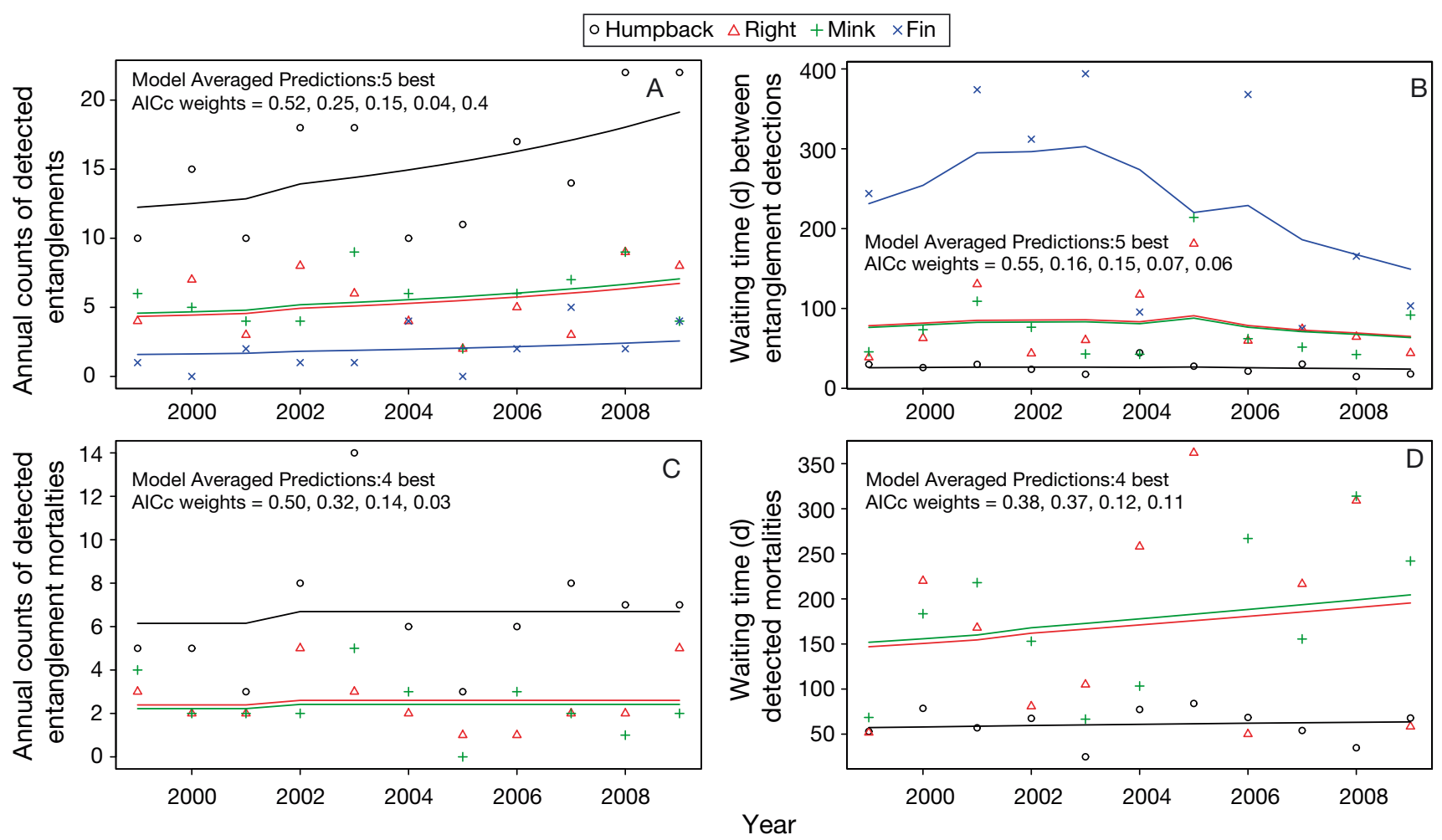

Fig. 3. Annual values plotted against resulting generalized linear model fits to (A) counts of entanglements, (B) waiting times between entanglements, (C) counts of mortalities due to entanglement, and (D) waiting times between detected entanglement mortalities for (A,B) 4 species and (C,D) 3 species of large whales (for full species names see Fig. 2) monitored in the Atlantic US exclusive economic zone (EEZ) from 1999 to 2009. AICc: corrected Akaike's information criterion

Table 2. Results of logistic regression models of probability that a detected entanglement was a mortality or serious injury for 4 species of baleen whales (Balaenoptera acutorostrata, B. physalus, Eubalaena glacialis, Megaptera novaeangliae) in the Atlantic EEZ from 1999 to 2009. See Table 1 for abbreviations

\begin{tabular}{|lrcccc|}
\hline Model & K & AICc & $\Delta$ AICc & $\begin{array}{c}\text { AICc } \\
\text { weight }\end{array}$ & $\begin{array}{c}\text { Cumulative } \\
\text { weight }\end{array}$ \\
\hline Quadratic(Year) & 3 & 422.38 & 0 & 0.43 & 0.43 \\
Year & 2 & 422.41 & 0.03 & 0.43 & 0.86 \\
Constant & 1 & 425.5 & 3.12 & 0.09 & 0.95 \\
Species + Year & 5 & 427.35 & 4.97 & 0.04 & 0.99 \\
Species & 4 & 429.96 & 7.58 & 0.01 & 1 \\
Species $\times$ Year & 8 & 431.97 & 9.59 & 0 & 1 \\
Species + Factor(Year) & 288 & 8526.76 & 8104.38 & 0 & 1 \\
\hline
\end{tabular}

Not surprisingly, results from our simulation experiments showed the marked influence that sample size (number of events tallied) and effect sizes (overall reductions in event rates) have on the chances of detecting a true change in event rates (Fig. 6). A $20 \%$ reduction in entanglement rate had little chance of being detected in the simulations even when the base rate was 15 entanglements per year. More substantial effect sizes stood a fair chance of being detected when initial rates were 10 or more per year,

period because there was no clear winner among competing models (AICc difference of $>8$; Tables 3 \& 4). In nearly all instances of evidence supporting change elements, the estimated parameters led to models predicting that events were more frequent toward the end of the study period. Increasing event rates through time was most evident for humpback and fin whale entanglements, for which there was no evidence to support a constant event rate. and models of waiting times (glm, gamma with inverse link) were slightly more powerful at detecting true change than those relying on count data. Models of event times were substantially more powerful than those for counts or waiting times but, surprisingly, the Type I error rates for this approach were also substantially higher $(\sim 40 \%)$ than normally accepted in the classical statistical paradigm. Including $2 \%$ annual population growth with a concomi- 


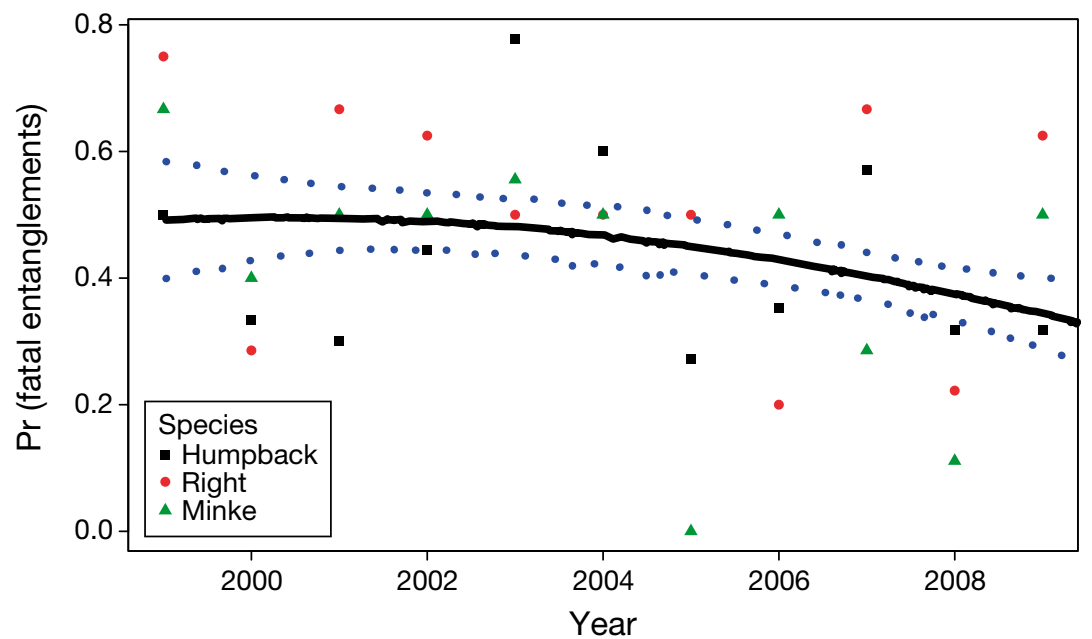

Fig. 4. Annual proportions of detected entanglements declared to be mortalities or serious injuries plotted against a logistic regression model fit to events built on continuous time for 3 species of large whales monitored in the Atlantic US EEZ from 1999 to 2009. Note that competing models that included species as a predictor had little influence on the model-averaged predicted proportions. Points are raw species within year proportions. Line is model-averaged using the 4 best AICc weights $=0.43,0.43,0.09,0.04$. Fitted line \pm 1 SE. See Fig. 2 for full species names

\section{Entanglements}
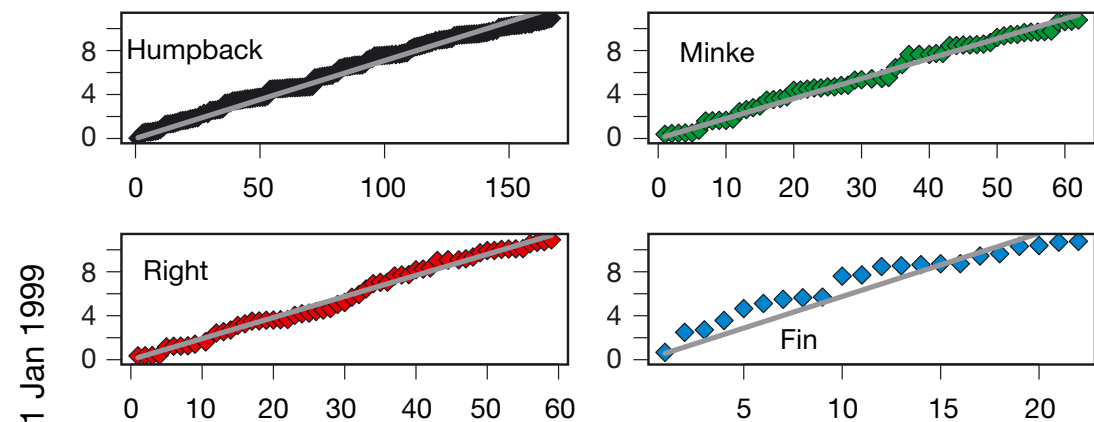

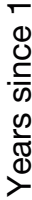

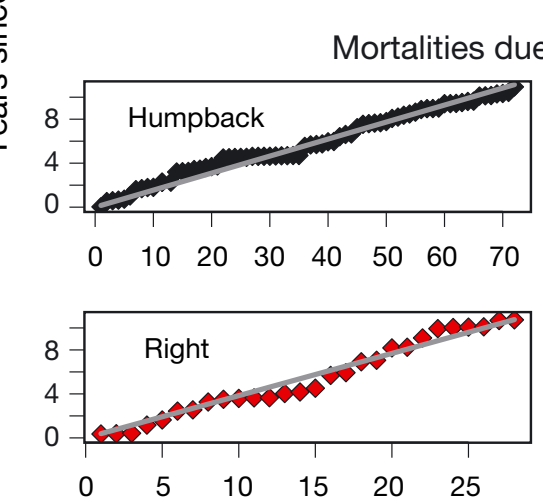

to entanglement
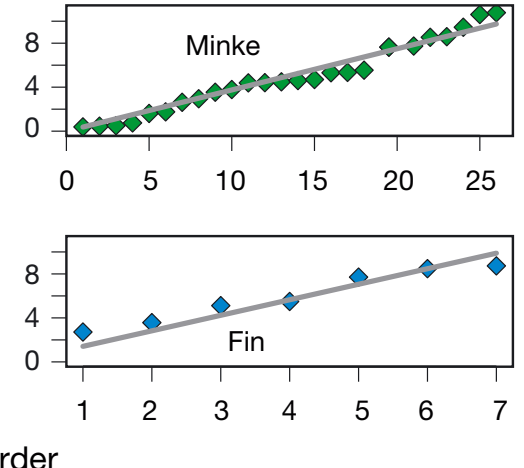

Fig. 5. Plots of event times (years since 1 January 1999) by order of occurrence for entanglement or mortalities or serious injuries due to entanglement events for 4 species of large whales (see Fig. 2 for full species names) monitored in the Atlantic US EEZ from 1999 to 2009. A conservation measure that reduces rates of occurrence would cause plots to deflect upward (more time between events). Note the different $x$-axis scales tant increase in mortality events slightly lowered the rejection rate of false null hypotheses (Fig. 6), but modest and large effect sizes were readily detected.

\section{DISCUSSION}

The data available for measuring fisheries interactions with large whales, as with many situations in conservation biology, are often too sparse to support strong conclusions about the efficacy of attempts to mitigate those interactions. As our simulations showed, rates of detected entanglement-related mortality must be reduced substantially (on the order of $50 \%$ or more) to have much of a guarantee of a change over short time frames (10 yr) being detected. A solution to this dilemma may exist if multiple rare events can be linked in a common analysis or concomitant predictors can be incorporated (Dixon et al. 2005). Analyzing a similar time series of events, Pace (2011) recognized that sums of Poisson processes remain Poisson, and thus he pooled detected ship strikes of large whales to achieve greater power in his evaluations. In our analysis of the efficacy of rules to mitigate fisheries interactions with large whales, we used the idea that modifications to gear may affect interaction rates with multiple species, and combined 4 species into a common set of analyses to increase the power of our analyses.

Through our examination of detection times of entanglements and entanglement-related deaths, we found no evidence to suggest that the frequency of entanglements or entanglement-related mortality substantially abated during 1999-2009. The lack of evidence to support declining frequencies of entanglement or serious injury due to entanglement remains disappointing, given that considerable time and expense have 
Table 3. Model comparisons of generalized least squares fits (auto-correlated error structure) to detected mortalities and serious injuries from gear entanglement predicted by competing models on their order of occurrence, for Megaptera novaeangliae, Eubalaena glacialis, and Balaenoptera acutorostrata. See Table 1 for abbreviations

\begin{tabular}{|c|c|c|c|c|c|}
\hline \multirow{2}{*}{ Model } & \multirow[b]{2}{*}{ K } & \multirow[b]{2}{*}{$\mathrm{AICc}$} & \multicolumn{2}{|c|}{ Mortalities } & \multirow[b]{2}{*}{$\begin{array}{c}\text { Cumulative } \\
\text { weight }\end{array}$} \\
\hline & & & $\triangle \mathrm{AICC}$ & $\begin{array}{c}\text { AICc } \\
\text { weight }\end{array}$ & \\
\hline \multicolumn{6}{|l|}{ Humpback whale } \\
\hline Change after 2002 & 5 & -24.69 & 0 & 0.75 & 0.75 \\
\hline Linear regression & 4 & -21.32 & 3.38 & 0.14 & 0.88 \\
\hline Quadratic & 5 & -19.97 & 4.72 & 0.07 & 0.95 \\
\hline Change after 2008 & 5 & -19.11 & 5.58 & 0.05 & 1 \\
\hline \multicolumn{6}{|l|}{ Right whale } \\
\hline Linear regression & 4 & 30.39 & 0 & 0.51 & 0.51 \\
\hline Change after 2008 & 5 & 32.21 & 1.82 & 0.21 & 0.71 \\
\hline Quadratic & 5 & 32.73 & 2.33 & 0.16 & 0.87 \\
\hline Change after 2002 & 5 & 33.16 & 2.76 & 0.13 & 1 \\
\hline \multicolumn{6}{|l|}{ Minke whale } \\
\hline Quadratic & 5 & 36.59 & 0 & 0.53 & 0.53 \\
\hline Linear regression & 4 & 37.71 & 1.12 & 0.3 & 0.83 \\
\hline Change after 2002 & 5 & 39.95 & 3.36 & 0.1 & 0.93 \\
\hline Change after 2008 & 5 & 40.76 & 4.16 & 0.07 & 1 \\
\hline
\end{tabular}

Table 4. Model comparisons of generalized least squares (auto-correlated error structure) fits to entanglement detections predicted by competing models on their order of occurrence, for Megaptera novaeangliae, Eubalaena glacialis, Balaenoptera acutorostrata, and B. physalus. See Table 1 for abbreviations

\begin{tabular}{|lccccc|}
\hline \multirow{2}{*}{ Model } & \multicolumn{5}{c}{ Entanglements } \\
\cline { 2 - 3 } & $\mathrm{K}$ & AICC & $\Delta$ AIC & $\begin{array}{c}\text { AICC } \\
\text { weight }\end{array}$ & $\begin{array}{c}\text { Cumulative } \\
\text { weight }\end{array}$ \\
\hline Humplback whale & & & & & \\
Quadratic & 5 & -289.16 & 0 & 0.93 & 0.93 \\
Change after 2008 & 5 & -282.87 & 6.28 & 0.04 & 0.97 \\
Change after 2002 & 5 & -282.18 & 6.98 & 0.03 & 1 \\
Linear regression & 4 & -278.55 & 10.61 & 0 & 1 \\
Right whale & & & & & \\
Change after 2008 & 5 & -20.37 & 0 & 0.46 & 0.46 \\
Linear regression & 4 & -19.66 & 0.71 & 0.33 & 0.79 \\
Quadratic & 5 & -17.5 & 2.87 & 0.11 & 0.9 \\
Change after 2002 & 5 & -17.3 & 3.07 & 0.1 & 1 \\
Minke whale & & & & & \\
Quadratic & 5 & 5.42 & 0 & 0.34 & 0.34 \\
Linear regression & 4 & 5.71 & 0.3 & 0.29 & 0.63 \\
Change after 2002 & 5 & 5.8 & 0.38 & 0.28 & 0.91 \\
Change after 2008 & 5 & 8.02 & 2.61 & 0.09 & 1 \\
Fin whale & & & & & \\
Quadratic & 5 & 33.46 & 0 & 0.94 & 0.94 \\
Change after 2002 & 5 & 39.26 & 5.81 & 0.05 & 0.99 \\
Linear regression & 4 & 44.49 & 11.03 & 0 & 1 \\
Change after 2008 & 5 & 45.11 & 11.65 & 0 & 1 \\
\hline
\end{tabular}

that events became more frequent through the study period. Our results indicate a clear need for different or additional mitigation measures.

At least 2 indirect lines of evidence support our conclusion that mitigation measures deployed during our study period were insufficient to reduce large whale and fisheries interactions to acceptable levels. Robbins (2011, 2012) analyzed entanglement rates of humpback whales in the Gulf of Maine and concluded that new entanglements were either constant or increasing during a time frame largely overlapping ours. Similarly, Knowlton et al. (2012) evaluated rates of entanglement scar acquisition by North Atlantic right whales and estimated a nearly constant rate of new scarring from 1999 to 2006. Knowlton et al. (2012) also detected an increase in the rate of right whales carrying gear and an increase in the number of whales that they determined as seriously injured. (Their definition varies somewhat from NMFS definition.) More directly, van der Hoop et al. (2013) evaluated stranding records and found significant increases in entanglement and vessel strike mortality probabilities for large whales from 1990 through 2009. In addition, they found no significant change in the local intensity of mortalities before and after 2003, which implies that much of the detected increase in our first model was due to increased lethal fisheries interactions.

It is possible that entanglements and related mortalities declined during the period but that the detectability of events increased, or growing whale populations produced increased numbers of events despite a declining prevalence. Based on studies of acquisition rates of non-lethal entanglement scars on humpback whales, only a small fraction of entanglements been spent involving stakeholders in a process to develop measures (gear modifications) specifically designed to mitigate such interactions. Most of the evidence from evaluating the event data suggests are detected (Robbins 2011). Thus, variable detection rates could significantly alter waiting times inherent in our records. However, we are aware of no evidence to suggest that detectability of events has 

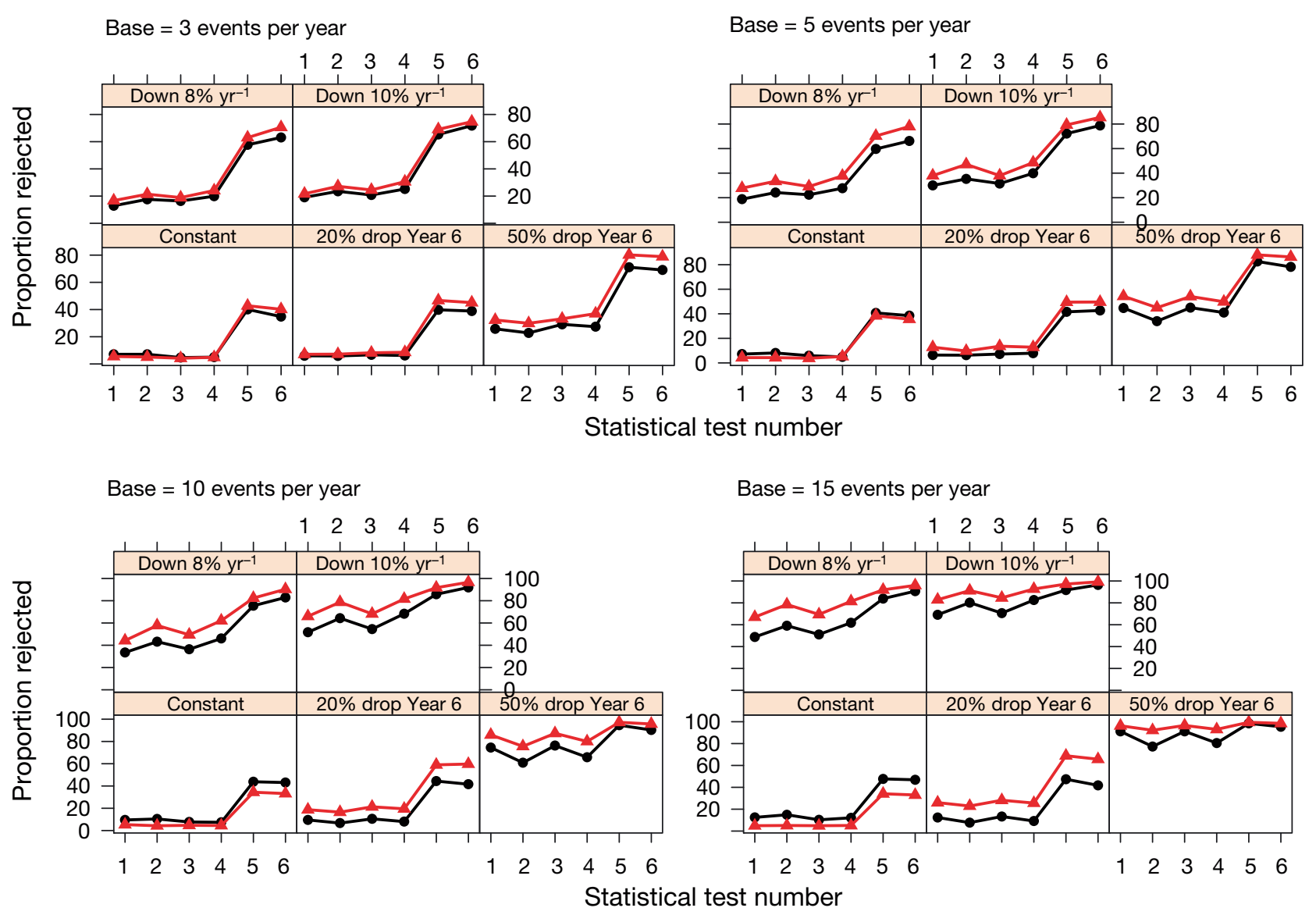

Fig. 6. Results of simulations examining the power of 6 different deviance tests to detect differences from constant event rates $\left(H_{0}\right)$ when rates increase linearly with populations and concomitant event rate growth of $2 \%(\bullet)$ and no growth $(\boldsymbol{\Delta})$. Plot groupings portray different base event rates modified with 5 different rate-reducing effects (see 'Methods' for a description of experimental conditions and specific tests 1-6). Note that a difference in a trial occurs when the appropriate statistical test statistic is rejected at $\alpha=0.05$, and rejecting when $H_{0}$ is true (no difference exists $=$ Constant) is a Type I error

changed. As noted earlier, detections come from a wide range of observers, including biologists, commercial fishermen, commercial whale watchers, recreational boaters, and others. No large changes in large whale research and management occurred during our study, thus there was relatively constant effort exerted in detecting entanglements. Many detections came from naturalists on whale watch boats operating in the Gulf of Maine, a multi-vendor enterprise that has been operating at about the same level for $>20$ yr. Anecdotally, we note that this haphazard collection process was able to detect a significant mortality event of humpbacks that occurred during 2003 in the Gulf of Maine and not associated with entanglement (Gulland 2006). The entanglement rates of right whales and humpback whales were correlated. This relationship was likely evident because events are frequent enough for both of these 2 species to detect a similarly increasing pattern through time, whereas fin whales showed no correlation with either because the detections are less frequent. Many humpback and right whales frequent the Gulf of Maine during late spring and summer. While not completely overlapping in time and space, they likely show enough co-occurrence with fixed fishing gear, especially pot gear, to show a similar pattern. North Atlantic right whale population growth has been estimated at $2.6 \%$ per year (Waring et al. 2011). Although precise population growth rates were not available for Gulf of Maine humpback whales for the period in question (Robbins 2007, Waring et al. 2011), we assumed a $2 \%$ per year increase for the purpose of simulation. Based on these simulations, small improvements resulting from gear modifications could be obscured by opposing effects of population growth, but the substantial true decreases hoped for by the ALTWRT and required to meet the mandates of the MMPA would not be masked. 
NMFS is mandated to reduce human-caused mortality of marine mammals to levels not compromising stock viability. In agreement with other studies, our analysis causes us to strongly reject the notion that significant conservation gains resulted from the first $10 \mathrm{yr}$ of ALWTRT negotiated incremental mitigation measures. The key word here is significant reductions which would not likely be masked by small amounts of population growth or shifts in whale and gear distribution. Further, our findings support decisions by NMFS to impose further conservation measures such as the recently instituted 'ground line rule', and to seek other means of reducing whale-gear interactions. However, the lack of progress during the first $10 \mathrm{yr}$ is cause for concern. That the development of measures to reduce large whale entanglements has been incremental may have been predicted, given the lack of fundamental knowledge of how entanglements occur (Johnson et al. 2007) and the economic value of the fisheries responsible for entanglements (Myers et al. 2007). Measured approaches seem warranted when knowledge is lacking and economic costs are potentially high. What seems to have received little weight in the evolution of rules was that, in the early stages, an analysis of right whale demographics concluded that the species, one of the most critically endangered cetaceans in the world, was headed for extinction if human-caused mortality was not reduced (Fujiwara \& Caswell 2001). We believed that, to be effective, mitigation measures would produce substantial direct reductions in mortality (biological response). However, we may be experiencing a common problem in conservation: we are attempting to evaluate a process without any explicitly measurable goals or trade-offs (Lonergan 2011). Although the MMPA does provide an explicit goal to reduce takes below a stock's 'potential biological removal' (PBR) in $6 \mathrm{mo}$, that goal was not achieved for most large whale stocks found off the northeast USA. PBR is typically exceeded even when using confirmed human-caused mortalities as a measure, which is likely a biased low accounting of takes. Moreover, it has not proven useful to compare observed takes to the PBR threshold as an 'on-off' switch approach to evaluating effectiveness of management actions, where observed takes which are below PBR indicate effective actions, and takes which exceed PBR indicate ineffective measures. Observed entanglements and entanglement-related mortalities have frequently exceeded PBR (van der Hoop et al. 2013) for more than a decade for western North Atlantic baleen whales with no apparent catastrophic consequences for these stocks (Waring et al.
2011). Without more sensitive effectiveness measures, the lack of definitive positive results such as ours will be a frequent result of effectiveness evaluations. In this paper, we have produced an evaluation of management action effectiveness despite the meager data available for that evaluation.

Acknowledgements. We are especially grateful to the US and the Canadian Maritime Provinces and Newfoundland stranding and entanglement networks, and the Atlantic Large Whale Disentanglement Network, whose members searched for and examined whales both live and dead. It is a difficult, dirty, and ceaseless job that deserves special recognition. The United States Coast Guard was instrumental in conveying sightings reported by mariners, investigating carcasses at sea, and assisting in disentanglement efforts. We are also grateful to the staff of the Provincetown Center for Coastal Studies (PCCS), New England Aquarium, Whale Center of New England (WCNE), NOAA aerial survey teams, Wildlife Trust, the states of Florida and Georgia, Northeast Fisheries Observer Program, Marine Animal Response Society, New Brunswick Museum, Atlantic Veterinary College, Grand Manan Whale and Seabird Research Station, Whale Release and Stranding, and many others for providing the sightings that have allowed this work to be conducted.

\section{LITERATURE CITED}

Anderson DR (2008) Model based inference in the life sciences: a primer on evidence. Springer, New York, NY

Dixon PM, Ellison AM, Gotelli NJ (2005) Improving the precision of estimates of rare events. Ecology 86:1114-1123

Fujiwara M, Caswell H (2001) Demography of the endangered North Atlantic right whale. Nature 414:537-541

Gulland FMD (2006) Review of the Marine Mammal Unusual Mortality Event Response Program of the National Marine Fisheries Service. NOAA Tech Memo NMFS-OPR-33. US Dept of Commerce, Office of Protected Resources, Silver Spring, MD

Henry AG, Cole TVN, Garron M, Hall L (2011) Mortality and serious injury determinations for baleen whale stocks along the Gulf of Mexico, United States and Canadian eastern seaboards, 2005-2009. Northeast Fish Sci Cent Ref Doc 11-18. US Dept of Commerce, Northeast Fisheries Science Center, Woods Hole, MA

Johnson AJ, Kraus SD, Kenny JF, Mayo CA (2007) The entangled lives of whales and fisherman: can they coexist? In: Kraus SD, Rolland RM (eds) The urban whale: North Atlantic right whales at the crossroads. Harvard University Press, Cambridge, MA, p 380-408

> Knowlton AR, Hamilton PK, Marx MK, Pettis HM, Kraus SD (2012) Monitoring North Atlantic right whale Eubalaena glacialis entanglement rates: a $30 \mathrm{yr}$ retrospective. Mar Ecol Prog Ser 466:293-302

Lonergan M (2011) Potential biological removal and other currently used management rules for marine mammal populations: a comparison. Mar Policy 35:584-589

McCullagh P, Nelder JA (1989) Generalized linear models, 2nd edn. Chapman \& Hall, London

Moore MJ, Knowlton AR, Kraus SD, McLellan WA, Bonde RK (2005) Morphomety, gross morphology and available 
histopathology in North Atlantic right whale (Eubalaena glacialis) mortalities (1970-2002). J Cetacean Res Manage 6:199-214

Myers RA, Boudreau SA, Kenney RD, Moore MJ, Rosenberg AA, Sherrill-Mix SA, Worm B (2007) Saving endangered whales at no cost. Curr Biol 17:R10-R11

National Marine Fisheries Service (2007) Taking of marine mammals incidental to commercial fishing operations; Atlantic large whale take reduction plan — final rule. Fed Reg 72:57104-57194

National Marine Fisheries Service (2008) Taking of marine mammals incidental to commercial fishing operations; Atlantic large whale take reduction plan - final rule. Fed Reg 73:51228-51242

Pace RM (2011) Frequency of whale and vessel collisions on the US Eastern seaboard: ten years prior and two years post ship strike rule. Northeast Fish Sci Cent Ref Doc 11-15. US Dept of Commerce, National Marine Fisheries Service, Woods Hole, MA. http://nefsc.noaa.gov/publications/

Pinheiro JC, Bates DM (2000) Mixed-effects models in S and S-PLUS. Statistics and Computing Series. SpringerVerlag, New York, NY

R Development Core Team (2011) R: a language and environment for statistical computing. R Foundation for Sta-

Editorial responsibility: Eric Gilman,

Honululu, Hawaii, USA tistical Computing, Vienna. www.R-project.org

Robbins J (2007) Structure and dynamics of the Gulf of Maine humpback whale population. $\mathrm{PhD}$ thesis, University of St. Andrews

Robbins J (2011) Scar-based inference into Gulf of Maine humpback whale entanglement: 2009. Order no. EA133F09CN0253. Report to the National Marine Fisheries Service, Woods Hole, MA

Robbins J (2012) Scar-based inference into Gulf of Maine humpback whale entanglement: 2010. Order no. EA133F09CN0253. Report to the National Marine Fisheries Service, Woods Hole, MA

van der Hoop JM, Moore MJ, Barco SG, Cole TVN and others (2013) Assessment of management to mitigate anthropogenic effects on large whales. Conserv Biol 27:121-133

Waring GT, Josephson E, Maze-Foley K, Rosel PE (eds) (2011) U.S. Atlantic and Gulf of Mexico marine mammal stock assessments - 2010. NOAA Tech Memo NMFS NE 219. National Marine Fisheries Service, Woods Hole, MA. www.nefsc.noaa.gov/nefsc/publications/

Williams R, Gero S, Bejder L, Calambokidis J, Kraus S (2011) Underestimating the damage: interpreting cetacean carcass recoveries in the context of the Deepwater Horizon/BP incident. Conserv Lett 4:228-233

Submitted: July 15, 2013; Accepted: July 19, 2014

Proofs received from author(s): October 17, 2014 